\title{
Acquisition of Staphylococcus aureus by Patients in Cubicles
}

\author{
M. T. PARKER,* M.D., DIP.BACT. ; MADELEINE JOHN,* B.SC. ; \\ R. T. D. EMOND, $\dagger$ M.B., CH.B., M.R.C.P., D.T.M.\&H. ; K. A. MACHACEK, $†$ M.D., D.P.H.
}

Brit. med. F., 1965, 1, 1101-1105

Much of the sepsis among hospital patients is caused by a relatively small number of endemic strains of Staphylococcus aureus which are usually resistant to several antibiotics (Williams, 1959 ; Parker and Jevons, 1963). These " hospital staphylococci" are to be found not only in septic lesions but also in the nose and on other body surfaces of many members of the hospital population. Indeed, symptomless carriers usually outnumber clinically infected patients, and are probably responsible for the maintenance and spread of these organisms in hospitals. Acquisition of antibiotic-resistant Staph. aureus in hospital is generally attributed to the combined effect of antibiotic therapy and cross-infection (Barber, 1947); the sensitive bacterial flora is suppressed by the antibiotics and is replaced by resistant organisms derived from other patients or from members of the staff. It might be possible, therefore, to limit the acquisition of antibiotic-resistant Staph. aureus either by controlling the amount and nature of the antibiotic therapy (Barber, Csillag, and Medway, 1958 ; Barber, Dutton, Beard, Elmes, and Williams, 1960) or by isolating the patients found to be infected with certain organisms. The isolation of carriers is certainly a valuable means of preventing the spread of particular strains of Staph. aureus, but it presents great practical difficulties, especially in hospitals consisting mainly of large undivided wards (Williams, Noble, Jevons, Lidwell, Shooter, White, Thom, and Taylor, 1962).

It is important to find out, therefore, whether the physical subdivision of wards, either alone or in combination with the segregation of carriers of particular staphylococcal strains (Shooter, Thom, Dunkerley, Taylor, Parker, John, and Richards, 1963), might play a part in the control of endemic hospital infection. For this reason we studied the nasal carrier state of patients in an infectious diseases hospital who were confined to cubicles-that is, rooms in which the structural separation between patients was provided by partitions which reached from floor to ceiling, but were cared for by a common medical, nursing, and domestic staff. A large proportion of the patients received antibiotics while in hospital.

The aim of the investigation was to study the carriage of Staph. aureus in the nose by all the patients admitted to the ward, to estimate the rate of acquisition of new strains, and to determine the relative importance of the staff and of the other patients as sources of infection.

\section{Ward Design and Management}

The ward was a single-storied building in the form of a cross, with five cubicles for patients on each arm (see Diagram). In the centre there was a kitchen and a treatment-room, while at the end of each arm there was a sluice-room and a lavatory. Two bathrooms served the whole ward. The doors of cubicles No. 1-10 opened on to a veranda enclosed by glass, but those of cubicles No. 11-20 opened on to an exposed veranda. Each cubicle had a window in the external wall. All were equipped with the usual ward furniture, and also had a wash-basin, a thermometer-holder, and a set of hooks for gowns. The cubicles usually contained only one patient, but sometimes two

* Cross-Infection Reference Laboratory, Colindale, London. t Coppett's Wood Hospital, London. members of a family, or two children with the same illness, shared a cubicle.

The rooms were cleaned each morning by the domestic staff. First, the furniture was dusted with a damp cloth kept for this purpose in each room; the floor was then cleaned with a Tellus vacuum-cleaner and finally mopped with $1 \%$ Sudol. The

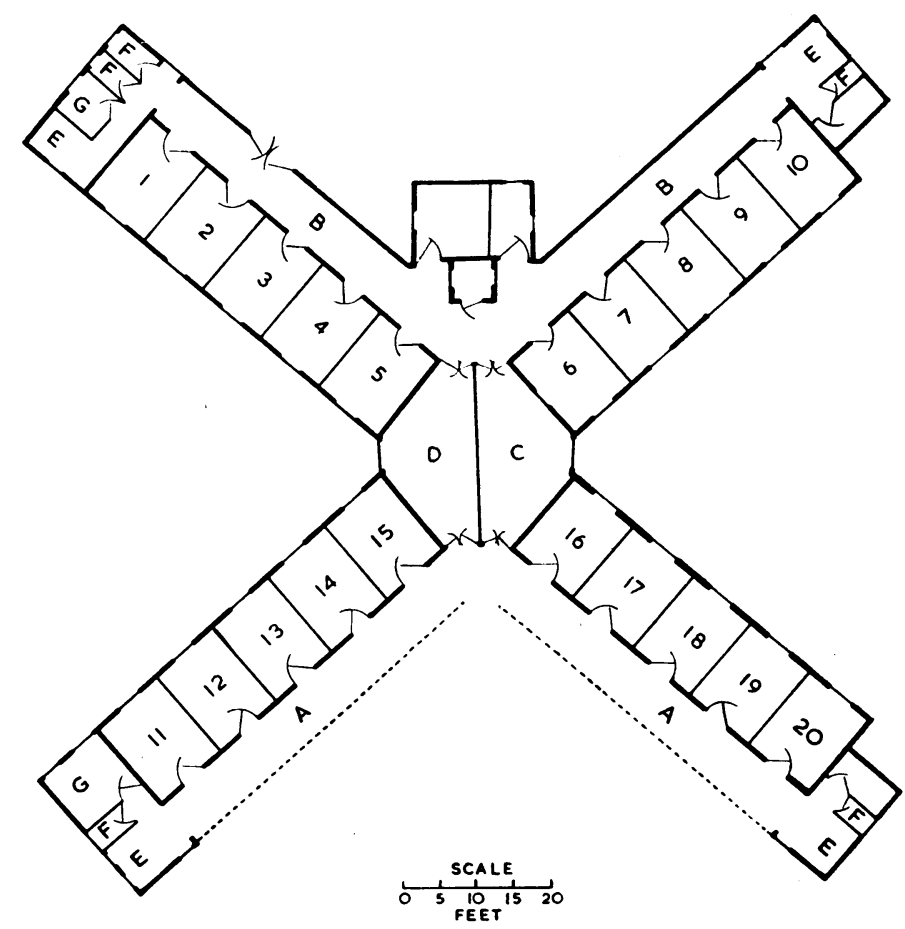

Plan of the cubicle ward. 1-20, Cubicles. A, Exposed veranda. B, Enclosed veranda. C, Kitchen. D, Treatment-room. E, Sluice-room.

domestic staff did not wear gowns, but did not touch the patients or their bedding. When a patient was discharged the room was thoroughly cleaned, and the floor, furniture, and mattress-cover were washed with $1 \%$ Sudol. After this the windows were left open for as long as possible before the next patient was admitted. Blankets and curtains were either autoclaved or sent to the laundry to be washed with soap and water at $45^{\circ} \mathrm{C}$. Unsoiled sheets were boiled, but soiled sheets were first soaked in $1 \%$ Sudol.

The nurses were responsible for all the patients in the ward, and had been specially trained in the techniques of nursing patients with infectious diseases. Masks were not used, but a gown kept in the cubicle was always worn when the patient or his bedding was touched. After removing her gown, the nurse washed her hands with Cidal soap and dried them on a paper towel. All crockery, bedpans, and urinals were sterilized by boiling. Medical equipment, such as electric suckers and oxygen apparatus, and televisions sets were wiped with disinfectant before being removed from a cubicle. Books and papers were destroyed after use. Patients were not allowed to enter cubicles other than their own, and did not use the bathroom or lavatory until they had reached a late stage of convalescence and were thought no longer to be infectious. The 
medical staff followed the same routine of gowning and handwashing as the nursing staff. Visiting was restricted to one close relative or friend from the same household. The visitor was allowed to enter the patient's room, but had to wear a gown, and was asked to wash his hands before leaving the hospital.

\section{Bacteriological Methods}

A nasal swab was obtained from each patient as soon as possible after admission to the ward and on each subsequent Monday and Thursday during the stay in hospital, and from each member of the medical, nursing, and domestic staff once a week. Dry cotton-wool swabs were used, and both anterior nares were sampled. The regular twice-weekly and weekly swabbing was made with plain cotton-wool swabs, which were transported without delay to the laboratory and inoculated on to horse-blood-agar plates. The swabs used for sampling on admission were impregnated with powdered charcoal and were stabbed immediately after use into a transport medium (Stuart, Toshach, and Patsula, 1954). They were taken to the laboratory on the morning of the next working-day and cultured in the same manner.

Primary cultures were examined after overnight incubation at $37^{\circ} \mathrm{C}$., and again after a further day at room temperature. When a culture was overgrown with Proteus the original swab, which had been kept in the refrigerator in the meantime, was inoculated on to a salt-agar plate. Organisms resembling Staph. aureus, including representatives of all colonially distinguishable forms, were subcultured and tested for the production of coagulase. At least one culture from each positive plate was phage-typed and tested for resistance to antibiotics with an Oxoid multodisk containing the following quantities of antibiotic: penicillin 1.5 units, streptomycin $10 \mu \mathrm{g}$., tetracycline $10 \mu \mathrm{g}$., chloramphenicol $10 \mu \mathrm{g}$., erythromycin $10 \mu \mathrm{g}$. An organism was regarded as resistant if it grew right up to the disk or to within 1-2 $\mathrm{mm}$. of it.

A record was kept of the cubicle occupied by each patient on each day. A card was also completed for each patient: it gave a short summary of the clinical condition and recorded the presence of staphylococcal infection on admission or its development in the ward. The nature and duration of any treatment with antibiotics was also noted.

\section{Results}

The investigation was carried on for 15 months, from February 1962 to April 1963. In this time records were made of 468 patients, the whole of whose stay in the ward was included in the period of the study. Twenty-two of them had to be excluded, 12 because the collection of the first swab was delayed for more than 24 hours after admission, and a further 10 because their stay in the ward was so short that only one swab was obtained. The remaining 446 patients were observed, with regular twice-weekly nasal swabbing, for a total of 859 patientweeks. Most of those admitted to the ward were children or young adults (38\% under 10 years, $38 \% \quad 10-30$ years of age), and there was a slight excess of females ( $55 \%$ ), mainly in the age group of 10-30 years. Most of the patients were suffering from an infectious disease, and the rest from other medical illnesses.

In all, $43 \%$ of the patients received an antibiotic. The number and percentages receiving each individual antibiotic are given in Table I. Eleven of the patients were admitted with a staphylococcal infection, and a further five developed a staphylococcal lesion while in hospital (1.1 per 100 admissions ; 0.6 per 100 patient-weeks). The acquired infections-three boils, one whitlow, and one secondary infection of a pressure sore-were all relatively mild. All five were epidemiologically unconnected.

TABle I. - Numbers and Percentages of Patients Treated with Antibiotics

\begin{tabular}{ll|c|c}
\hline & & No. & \multicolumn{2}{|c}{$\%$} \\
\hline Tetracycline &. & 67 & $15 \cdot 0$ \\
Penicillin .. &. & 65 & $14 \cdot 6$ \\
Streptomycin &. & 46 & $10 \cdot 3$ (by injection $4 \cdot 3 \%$ ) \\
Neomycin .. &. & 19 & $4 \cdot 3$ \\
Chloramphenicol &. & 13 & 2.9 \\
Erythromycin &. & 8 & 1.8 \\
Paromomycin &. & 8 & $1 \cdot 8$ \\
Ampicillin .. &. & 2 & $0 \cdot 4$ \\
Methicillin .. &. & 1 & $0 \cdot 2$ \\
\hline Any antibiotic &. & 190 & $42 \cdot 6$ \\
\hline
\end{tabular}

\section{Nasal Carrier-rates}

Table II shows the carrier-rate of Staph. aureus by the patients on admission and in each of the first eight half-weeks of stay in the ward. Staph. aureus was obtained from $37 \%$ of the admission swabs; the carrier-rate for staphylococci resistant only to penicillin was $19 \%$, and for staphylococci resistant to two or more antibiotics including penicillin was $3 \%$. There was no significant change during the next few weeks in the total carrier-rate, but the proportion of patients carrying sensitive organisms fell slowly. The rate of carriage of Staph. aureus resistant only to penicillin remained fairly constant, but there was a small - rise-reaching $7 \%$ in the second and third weeks-in the percentage of patients carrying organisms resistant to two or more antibiotics. All of these multiple-resistant organisms were resistant to penicillin, and over $90 \%$ were resistant to tetracycline.

\section{Apparent Acquisition of New Strains of Staph. aureus}

Eighty-six strains of Staph. aureus not present in the admission swab were subsequently isolated from 76 of the 446 patients. It is possible, however, that some of these "acquisitions" may have been due to failure to detect staphylococci brought into hospital by the patients. We shall refer to them therefore as "apparent acquisitions."

The rate of apparent acquisition of new strains was 19.3 per 100 patients admitted. The corresponding rate for patients who received an antibiotic (23.2) was somewhat higher than the rate for patients who did not (16.5), but they stayed in hospital longer on average. We therefore calculated the number of apparent acquisitions per 100 weeks of exposure in the ward (Table III), and found that there was no significant difference between the two groups in the frequency with which new strains of Staph.aureus appeared in the nose; but the apparent acquisition of staphylococci resistant to two or more antibiotics

TABLE II.-Nasal Carriage of Staph. aureus in Relation to Length of Stay in Hospiial

\begin{tabular}{|c|c|c|c|c|c|c|c|c|c|c|c|c|c|c|}
\hline & \multicolumn{5}{|c|}{ Week in hospital: } & & \multicolumn{2}{|c|}{1} & \multicolumn{2}{|c|}{2} & \multicolumn{2}{|c|}{3} & \multicolumn{2}{|c|}{4} \\
\hline & & Twi & seel & swat & Jo.: & Admission & 1 & 2 & 3 & 4 & 5 & 6 & 7 & 8 \\
\hline $\begin{array}{l}\text { Total No. swabbed } \\
\% \text { carrying Staph. aureus } \\
\% \text { with Staph. aureus: S } \\
\% \text { with Staph. aureus: P } \\
\% \text { with Staph. aurexs: M }\end{array}$ & $\begin{array}{l}\cdots \\
\because \\
\cdots\end{array}$ & $\begin{array}{l}\cdots \\
\cdots \\
\cdots \\
\cdots\end{array}$ & $\begin{array}{l}\cdots \\
\cdots \\
\cdots\end{array}$ & $\begin{array}{l}\because \\
\because \\
\cdots\end{array}$ & $\begin{array}{l}\because \\
\because \\
\cdots \\
\cdots\end{array}$ & $\begin{array}{r}446 \\
37 \cdot 4 \\
18 \cdot 2 \\
18 \cdot 6 \\
3 \cdot 1\end{array}$ & $\begin{array}{r}446 \\
35 \cdot 2 \\
14 \cdot 8 \\
19 \cdot 0 \\
3 \cdot 8\end{array}$ & $\begin{array}{r}385 \\
34 \cdot 5 \\
14 \cdot 5 \\
18 \cdot 4 \\
4 \cdot 4\end{array}$ & $\begin{array}{r}280 \\
36 \cdot 1 \\
13.9 \\
20.7 \\
4.6\end{array}$ & $\begin{array}{r}188 \\
35 \cdot 6 \\
11 \cdot 2 \\
19 \cdot 1 \\
7 \cdot 4\end{array}$ & $\begin{array}{r}126 \\
34 \cdot 9 \\
11 \cdot 1 \\
17 \cdot 5 \\
7 \cdot 1\end{array}$ & $\begin{array}{r}86 \\
34 \cdot 9 \\
9 \cdot 3 \\
19 \cdot 8 \\
7 \cdot 0\end{array}$ & $\begin{aligned} 58 \\
27 \cdot 6 \\
8 \cdot 6 \\
15 \cdot 5 \\
3 \cdot 4\end{aligned}$ & $\begin{array}{r}3 \\
34 \cdot 9 \\
18 \cdot 6 \\
9 \cdot 3 \\
7 \cdot 0\end{array}$ \\
\hline
\end{tabular}

$\mathbf{S}=$ Sensitive to all antibiotics. $\mathbf{P}=$ Resistant only to penicillin. $M=$ Resistant to two or more antibiotics: all resistant to penicillin; $91 \%$ resistant to tetracycline; $53 \%$ resistant to streptomycin. 
occurred more quickly in patients who had received an antibiotic ( 3 per 100 patient-weeks) than in those who had not (1 per 100 patient weeks).

In the second half of Table III the rates of apparent acquisition per 100 patient-weeks were recalculated as if the patients had been swabbed only once a week, to facilitate comparison with other studies in which this was done. The results for the second and subsequent alternate swabs were excluded. Many of the new organisms detected by the twice-weekly swabbing were isolated only once, or were present intermittently. The rates of apparent acquisition based on weekly swabbing were therefore considerably lower than those obtained by including the results of all the swabs; they were 6.4 per 100

TABLE III.-Rates of Apparent Acquisition of New Strains of Staph. aureus per 100 Weeks of Exposure in Ward

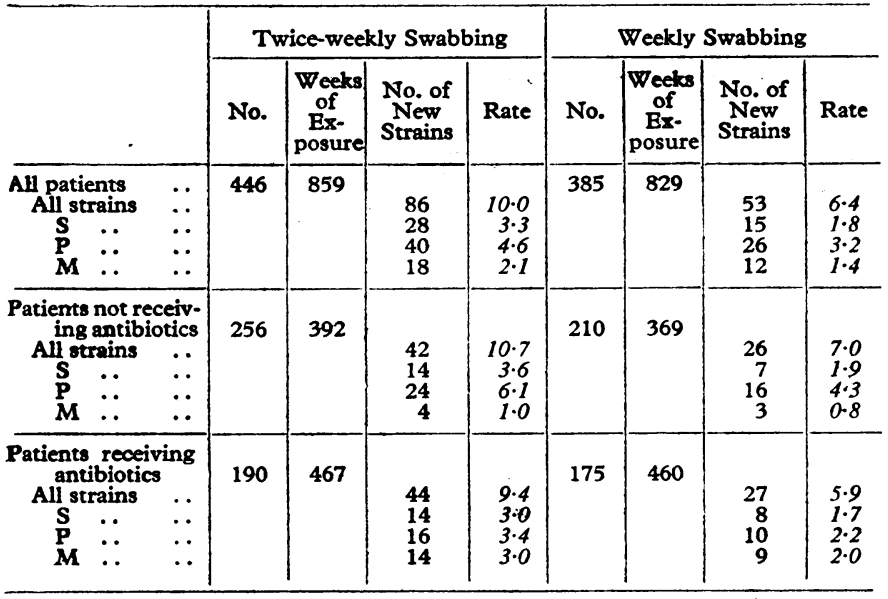

$S=$ Sensitive to all antibiotics.

$M=$ Resistant to two or more antibiotics.

TABLE IV.-Apparent Acquisition of New Strains of Staph. aureus. Numbers of New Strains in Each Half-week From the Time of Admission. In Italic: Rates of Apparent Acquisition per 100 Patient-weeks

\begin{tabular}{|c|c|c|c|c|c|c|c|c|c|}
\hline \multirow{2}{*}{\multicolumn{4}{|c|}{$\begin{array}{r}\text { Week in Hospital: } \\
\text { Twice-weekly swab No.: }\end{array}$}} & \multicolumn{3}{|c|}{1} & \multicolumn{2}{|c|}{2} & \multirow{2}{*}{$\frac{3}{5 \text { and } 6}$} \\
\hline & & & & \multicolumn{2}{|c|}{1} & 2 & 3 & 4 & \\
\hline \multicolumn{4}{|c|}{ All patients } & & \multirow{5}{*}{$\begin{array}{rr}385 & \\
20 & 5 \cdot 2 \\
7 & 1 \cdot 8 \\
9 & 2 \cdot 3 \\
4 & 1 \cdot 0\end{array}$} & \multirow{5}{*}{$\begin{array}{|rr|}280 & \\
15 & 5 \cdot 3 \\
6 & 2 \cdot 1 \\
6 & 2 \cdot 1 \\
3 & 1.0\end{array}$} & \multirow{4}{*}{$\begin{array}{rr}188 & \\
6 & 3.2 \\
3 & 1.6 \\
1 & 0.5 \\
2 & 1.0\end{array}$} & \multirow{13}{*}{$\begin{array}{rr}212 & \\
6 & 2.8 \\
1 & 0.5 \\
3 & 1.4 \\
2 & 0.9\end{array}$} \\
\hline New & strains: ail & & $\cdots$ & 32 & $7 \cdot 2$ & & & & \\
\hline , & $\mathbf{S}$ & . & $\cdots$ & 99 & $\begin{array}{l}2 \cdot 0 \\
3 \cdot 8\end{array}$ & & & & \\
\hline " & $\mathbf{M}$ & $\because$ & $\because$ & 6 & $\begin{array}{l}3 \cdot 8 \\
1 \cdot 3\end{array}$ & & & & \\
\hline \multicolumn{4}{|c|}{ Patients no" receiving antibiotics: } & & & & & & \\
\hline \multicolumn{2}{|c|}{$\begin{array}{l}\text { No. swabbed ail } \\
\text { New strains: all }\end{array}$} & .. & $\because$ & $\begin{array}{r}256 \\
17\end{array}$ & $6 \cdot 6$ & $\begin{array}{r}210 \\
15\end{array} 7 \cdot 2$ & $\begin{array}{rr}130 \\
6 & 4.6\end{array}$ & $\begin{array}{rr}79 & 2.6\end{array}$ & \\
\hline " & ", & . & $\ldots$ & 6 & $2 \cdot 3$ & 52.4 & $\begin{array}{ll}3 & 2 \cdot 3\end{array}$ & 22.6 & \\
\hline " & " & . & $\cdots$ & 9 & $3 \cdot 5$ & $94 \cdot 3$ & $\begin{array}{ll}3 & 2.3\end{array}$ & 0 & \\
\hline \multirow{3}{*}{\multicolumn{2}{|c|}{$\begin{array}{l}\text { Patients receiving ar } \\
\text { No. swabbed .il } \\
\text { New strains: all }\end{array}$}} & biot & & & & & & 0 & \\
\hline & & .. & $\ldots$ & & & 175 & 150 & 109 & \\
\hline & & . & $\ldots$ & 15 & 7.9 & $52 \cdot 8$ & 96.0 & $43 \cdot 7$ & \\
\hline " & S & . & 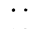 & $\begin{array}{l}3 \\
8 \\
8\end{array}$ & $\begin{array}{l}1.6 \\
4.2\end{array}$ & $2 I \cdot I$ & $\begin{array}{ll}3 & 2.0 \\
3 & 2.0\end{array}$ & $\begin{array}{ll}1 & 0.9 \\
1 & 0.9\end{array}$ & \\
\hline D, & M & .. & $\therefore$ & 4 & $2 \cdot 1$ & $\begin{array}{ll}3 & 1.7\end{array}$ & 32.0 & 21.8 & \\
\hline
\end{tabular}

SI = Sensitive to all antibiotics.

$\stackrel{P}{M}=$ Resistant to two or more antibiotics. patient-weeks for all Staph. aureus strains, and 1.4 per 100 patient-weeks for multiple-resistant strains. Those who received antibiotics acquired multiple-resistant strains two and a half times more rapidly than those who did not ( 2 and 0.8 per 100 patient-weeks respectively).

Table IV shows the number of new strains of Staph. aureus detected, and the rate of apparent acquisition, in each halfweek from the time of admission. Sixty per cent. of all the new strains were found in the first two twice-weekly swabbings. There was a steady fall in the total rate of apparent acquisition up to the fifth swabbing. This was mainly accounted for by a decreasing rate of appearance of new sensitive and penicillinresistant organisms, but new strains resistant to two or more antibiotics continued to appear at a steady rate for at least two weeks among patients treated with antibiotics.

\section{Nature and Possible Sources of New Strains of Staph. aureus}

The phage-typing patterns and antibiotic sensitivities of the organisms first appearing in the nose after admission to hospital suggested that they included very many different strains of Staph. aureus. We considered as members of a single strain those organisms which had phage-typing patterns differing by one strong lytic reaction or less (Williams and Rippon, 1952), and had the same sensitivity to penicillin and tetracycline. On these grounds the 86 organisms apparently acquired in the ward included representatives of at least 61 different strains of Staph. aureus. The largest number of patients colonized by a single organism was five.

We attempted to establish the sources from which the new staphylococci had been " acquired." Applying the same criteria for identifying a single strain, we compared each of the new staphylococci with all of those isolated from the nasal swabs of other patients during the previous week, and with all of those carried by a member of the ward staff during the month before and the month after the appearance of the new organism. In this manner we were able to identify a possible source for only 28 of the 86 staphylococci (33\%) which appeared to have been acquired in the ward (Table V).

On 13 occasions a member of the staff carried an organism that was indistinguishable from the one apparently acquired by the patient, and on 12 of them it was the only possible source to be identified. Once there were two possible sources-a patient and a member of the staff-and once two nurses were carrying a strain which subsequently appeared in the nose of a patient. The 12 (or possibly 13) staphylococci which might have been derived from members of the staff included nine distinct strains, and the greatest number that could possibly have arisen from a single source was four. This was a nurse who was a heavy nasal carrier of a type $80 / 81$ staphylococcus, and was on the staff of the ward for most of the period of the investigation.

Sixteen of the staphylococci that appeared to have been acquired by a patient were identical with organisms carried

TABLE V.-Probable Source of Staph. aureus Strains, and Rate of Apparent Acquisition from Each Source

\begin{tabular}{|c|c|c|c|c|c|c|c|c|c|c|c|c|c|}
\hline & & & & & \multicolumn{3}{|c|}{ All Patients } & \multicolumn{3}{|c|}{ One Patient per Cubicle } & \multicolumn{3}{|c|}{ Two Patients per Cubicle } \\
\hline & & & & & $\begin{array}{l}\text { Weeks of } \\
\text { Exposure }\end{array}$ & $\begin{array}{c}\text { No. of New } \\
\text { Strains }\end{array}$ & $\begin{array}{c}\text { Rate/100 } \\
\text { Patient-weeks }\end{array}$ & $\begin{array}{l}\text { Weeks of } \\
\text { Exposure }\end{array}$ & $\begin{array}{c}\text { No. of New } \\
\text { Strains }\end{array}$ & $\begin{array}{c}\text { Rate/100 } \\
\text { Patient-weeks }\end{array}$ & $\begin{array}{l}\text { Weeks of } \\
\text { Exposure }\end{array}$ & $\begin{array}{c}\text { No. of New } \\
\text { Strains }\end{array}$ & $\begin{array}{c}\text { Rate/100 } \\
\text { Patient-woeks }\end{array}$ \\
\hline $\begin{array}{l}\text { Twice-weekl } \\
\text { Acquisitio } \\
\text { Acquisitio } \\
\text { Acquisitio } \\
\text { No appare }\end{array}$ & $\begin{array}{l}\text { vabbing } \\
\text { om staff } \\
\text { om same } \\
\text { om differ } \\
\text { iource }\end{array}$ & $\begin{array}{l}. . \\
.0 \\
\text { cubicle } \\
\text { rent cub } \\
. .\end{array}$ & $\begin{array}{l}. \\
\ddot{e} \\
\text { oicle } \\
. . \\
\end{array}$ & $\begin{array}{l}. \\
\because \\
\because \\
. \\
\end{array}$ & 859 & $\begin{array}{c}12 \text { or } 13 \\
5 \\
10 \text { or } 11 \\
58 \\
\end{array}$ & $\begin{array}{c}1 \cdot 4-1 \cdot 5 \\
0.6 \\
1.2-1 \cdot 3 \\
6 \cdot 7 \\
\end{array}$ & 732 & $\begin{array}{c}10 \text { or } 11 \\
8 \text { or } 9 \\
50\end{array}$ & $\begin{array}{c}1.4-1.5 \\
1.1-1.2 \\
6.8\end{array}$ & 127 & $\begin{array}{l}2 \\
5 \\
2 \\
8 \\
\end{array}$ & $\begin{array}{l}1.6 \\
3.9 \\
1.6 \\
6 \cdot 3 \\
\end{array}$ \\
\hline Total . &.. &.. & .. &.. & & 86 & $10 \cdot 0$ & & 69 & $9 \cdot 4$ & & 17 & 13.4 \\
\hline $\begin{array}{l}\text { Weekly swat } \\
\text { Acquisitio } \\
\text { Acquisitio } \\
\text { Acquisitio } \\
\text { No appare }\end{array}$ & $\begin{array}{l}\text { g. . } \\
\text { om staff } \\
\text { om same } \\
\text { om differ } \\
\text { ource }\end{array}$ & $\begin{array}{l}. . \\
\text { cubicle } \\
\text { rent cub } \\
. .\end{array}$ & $\begin{array}{l}. . \\
. \\
\text { bicle } \\
\cdots \\
\end{array}$ & $\begin{array}{l}. \\
\ddot{2} \\
\ddot{.} \\
\end{array}$ & 829 & $\begin{array}{r}8 \\
3 \\
3 \\
39 \\
\end{array}$ & $\begin{array}{l}1.0 \\
0.4 \\
0.4 \\
4.7 \\
\end{array}$ & 703 & $\frac{7}{22}$ & $\begin{array}{l}1.0 \\
0.3 \\
5.0\end{array}$ & 126 & $\begin{array}{l}1 \\
3 \\
1 \\
4 \\
\end{array}$ & $\begin{array}{l}0.8 \\
2.4 \\
0.8 \\
3.2 \\
\end{array}$ \\
\hline Total & .. & .. & .. &.. & & 53 & $6 \cdot 4$ & & 44 & 6.3 & & 9 & $7 \cdot 1$ \\
\hline
\end{tabular}


by another patient; and in 15 instances the other patient was the only known source of the organism. Five of these apparent acquisitions were from a patient in the same cubicle as the recipient, but three of the pairs were siblings. The supposed source was in the next cubicle five times, and in the next but one twice; it was in an unrelated cubicle on a different "arm" of the cross four times, but there was an alternative source for one of these infections among the nurses. None of the acquisitions could be attributed to the previous occupant of a cubicle.

Table $\mathrm{V}$ also shows the rate of apparent acquisition of all new strains of Staph. aureus from known sources. On the basis of twice-weekly swabbing, 10 new strains were detected for each 100 weeks of exposure in the ward ; 1.4-1.5 of them could be attributed to infection from the staff, and 1.2-1.3 to infection from patients in other cubicles. A further 3.9 organisms per 100 weeks might have been acquired from another person in the same cubicle, but this was perhaps an overestimate due to the frequency with which members of a family shared a cubicle. The figures obtained by weekly swabbing were rather lower, but have a similar relation to each other and to the total rate of apparent acquisition.

\section{Discussion}

The acquisition of endemic hospital strains of Staph. aureus was not a serious problem in our cubicle ward, although over $40 \%$ of the patients admitted received an antibiotic, and no special measures were taken to detect and eliminate carriers of resistant organisms among the staff.

The total carrier-rate of Staph. aureus did not rise during the stay of the patients in the ward, and the proportion of patients carrying an organism resistant to two or more antibiotics increased only from $3 \%$ to $7 \%$. The few multipleresistant staphylococci acquired in the ward belonged to several different strains, none of which appeared to have become established endemically in the ward. The situation was therefore different from that usually seen in open wards. Among the surgical patients in St. Bartholomew's Hospital, for example, the total carrier-rate for Staph. aureus rose from $38 \%$ on admission to $58 \%$ after four weeks (Williams, Jevons, Shooter, Hunter, Girling, Griffiths, and Taylor, 1959), and over $20 \%$ of the patients remaining for four weeks or more in an open ward with no special facilities for isolation were carriers of tetracycline-resistant staphylococci (Williams et al., 1962).

It is difficult to arrive at a true estimate of the rate of acquisition of new strains of Staph. aureus by patients in hospital. Their state of nasal carriage before admission is usually inferred from the results of a single swab collected when they first enter the hospital. Staphylococci not present in the first swab but detected later-what we have termed "apparent acquisitions" -will almost certainly include some that were detectable only intermittently in the nose. How of ten the intermittent recovery of Staph. aureus from nasal swabs is due to imperfections in the sampling method, and how of ten to the intermittent presence of the organism in the nose, we do not know. If it occurred even in quite a small proportion of nasal carriers it would tend to overshadow a low rate of true acquisition of Staph. aureus.

Several facts suggest that a good deal of the apparent acquisition of new strains seen in the present investigation was spurious. A careful search failed to reveal a possible source for at least two-thirds of all the new strains. Most of these were sensitive to antibiotics, and resembled in every way the organisms isolated from other patients on admission to hospital. The rate of apparent acquisition of sensitive organisms was highest immediately after admission, and thereafter decreased steadily. It is unlikely, therefore, that more than a third of the 86 new strains detected in the noses of the 446 patients were really acquired in hospital.
The rates of apparent acquisition in the cubicle ward, calculated on the basis of weekly nasal swabbing (Table III), can be compared with those observed in certain other hospitals. For all patients in our ward the rate was 6.4 per 100 patientweeks for all strains of Staph. aureus, and 1.4 per 100 patientweeks for those resistant to two or more antibiotics. The rate of apparent acquisition of multiple-resistant staphylococci was 2 per 100 patient-weeks for those who received an antibiotic, and 0.8 per 100 patient-weeks for those who did not. In a recent investigation carried out by a committee of the Public Health Laboratory Service (Report, 1965), weekly nasal swabs from 4,100 patients in medical wards were examined. The average rate of apparent acquisition by patients treated with antibiotics was 9.4 per 100 patient-weeks for all Staph. aureus, and 6.3 per 100 patient-weeks for strains resistant to antibiotics other than penicillin. The corresponding rates for patients who did not receive any antibiotic were 9 and 3.7 respectively. In some medical wards, however, the rate of acquisition of multiple-resistant strains by those receiving antibiotics was as high as 10-12 per 100 patient-weeks. Shooter et al. (1963) carried out weekly swabbing of patients in a divided surgical ward. In the pre-operative half of the ward, where an attempt was made to exclude all patients carrying tetracycline-resistant organisms, the rate per 100 patient-weeks for all Staph. aureus was 9.9, and for tetracycline-resistant organisms 2 . On the post-operative side, where no segregation was practised, the corresponding rates were respectively 11.9 and 4.2. No likely source could be found for over half of the organisms " acquired" in this ward.

The patients in our cubicle ward appeared therefore to acquire strains of Staph. aureus that were sensitive to antibiotics, or resistant to penicillin only, at a rate not very different from that observed in open wards, but to acquire multipleresistant strains at a considerably lower rate. The patients in our ward were much younger on average than those in general medical and surgical wards; but the rate of apparent acquisition of multiple-resistant organisms was highest in the young patients. Indeed, if children under 10 years of age were excluded the rate was only 1 per 100 patient-weeks. It seems likely, therefore, that the physical segregation of our patients, which greatly reduced the chances of infection by the aerial route, was probably responsible for the infrequency with which they acquired "hospital staphylococci." Although it is not now possible to keep all hospital patients under similar conditions of physical isolation, the results of the present investigation suggest that a more extensive inquiry into the effects of ward subdivision on the spread of hospital staphylococci might be profitable.

The acquisition of Staph. aureus in the nose is probably a good index of exposure to infection, but our findings illustrate some of the difficulties of using serial nasal swabbing to measure it. The rate of apparent acquisition of all strains of Staph. aureus is an uncertain guide. Whether increasing the sensitivity of the sampling method would reduce the frequency of intermittent isolation from the nose is uncertain. The rate of appearance of new strains resistant to two or more antibiotics -organisms usually associated with the hospital environment, and seldom present in the nose on admission-is probably a more reliable measure of the contribution of the hospital to the patient's carrier state, especially if it is measured separately for those patients who have received antibiotics and those who have not. It may be important, however, also to distinguish between infections acquired from other patients and from the staff, because changes in ward design or ventilation might reduce the risk of one but not of the other.

\section{Summary}

We investigated the carriage of Staph. aureus in the nose by patients who were confined to cubicles in an infectious diseases hospital. 
There was no increase in the total carrier-rate during the stay of patients in the cubicle ward, and only a small rise in the percentage carrying staphylococci resistant to two or more antibiotics.

The rate of appearance of new strains of Staph. aureus on successive swabbing was investigated as a possible measure of the exposure of patients to infection. Isolation in cubicles did not have much effect on the rate of apparent acquisition of staphylococci sensitive to antibiotics or resistant only to penicillin, but it reduced considerably the rate for organisms resistant to two or more antibiotics.

It seemed likely that many of the "acquisitions" were artifacts, due to the intermittent isolation of organisms carried before admission. For this reason, the rate of apparent acquisition of multiple-resistant strains-which are less often found in the nose of patients on admission-is a more sensitive index of exposure to infection in hospital than the rate of apparent acquisition of all strains of Staph. aureus.

No likely source could be found for two-thirds of the apparent acquisitions. About half of the remainder could be attributed to infection from the staff and half to infection from patients in other cubicles. The rate of acquisition of strains from known sources might be a valuable measure of the effect of ward design on the risk of acquiring a hospital staphylococcus.

We are indebted to Dr. O. M. Lidwell and Dr. M. Patricia Jevons for helpful advice, and to Mr. G. McGimpsey and Mr. Ian Rae for technical assistance.

\section{REFERENCES}

Barber, M. (1947). f. Bath. Bact., 59, 373.

Csillag, A., and Medway, A. J. (1958). Brit. med. F., 2, 1377. Dutton, A. A. C., Beard, M. A., Elmes, P. C., and Williams, R (1960). Ibid., 1, 11 .

Parker, M. T., and Jevons, M. P. (1963). In Infection in Hospitals, edited by R. E. O. Williams and R. A. Shooter, p. 55. Blackwell, Oxford.

Report (1965). To be published.

Shooter, R. A., Thom, B. T., Dunkerley, D. R., Taylor, G. W., Parker, M. T., John, M., and Richards, I. D. G. (1963). Brit. med. \}., 2, 1567.

Stuart, R. D., Toshach, S. R., and Patsula, T. M. (1954). Canad. F. publ. Hlth, 45, 73.

Williams, R. E. O.'(1959). Lancet, 1, 190. Jevons, M. P., Shooter, R. A., Hunter, C. J. W Griffiths, J. D., and Taylor, G. W. (1959). Brit. med. F., 2, 658 . Noble, W. C., Jevons, M. P., Lidwell, O. M., Shooter, R A., White, R. G., Thom, B. T., and Taylor, G. W. (1962). Ibid., 2, 275

and Rippon. J. E. (1952). F. Hyg. (Lond.), 50, 320.

\title{
Crushed Chest Injury: Some Physiological Disturbances and Their Correction
}

\author{
J. M. REID,* M.B., CH.B., F.F.A. R.C.S., D.A., ; W. L. M. BAIRD, † M.B., CH.B., F.F.A. R.C.S., D.A.
}

Brit.'med. F., 1965, 1, 1105-1109

Although still a relatively uncommon injury, there is an increasing incidence of severe thoracic and pulmonary damage, due principally to high-speed motoring accidents. This type of injury, which was formerly associated with mining accidents, is commonly referred to as the crushed chest injury or stove-inchest. There may be multiple posterior or anterior fractures of ribs and fractures of the sternum or a mixture of such fractures.

Griffiths (1960), reviewing the literature, has summarized the advantages of treatment by intermittent positive-pressure ventilation (I.P.P.V.) over mechanical fixation. Nevertheless, the results remain somewhat disappointing.

In a series of 33 cases treated in the Respiratory Emergency Unit of Glasgow Royal Infirmary during the past two years it has become evident that an explanation for many disappointing results can be traced to our previous inability to measure the severity of the respiratory and metabolic disturbances that result from this form of trauma. The recent development of simple biochemical techniques and their application at the bedside now make it possible to assess rapidly the severity of the initial disturbances, to aid the selection of the correct treatment, and to follow at frequent intervals the effectiveness of the treatment.

\section{Respiratory and Metabolic Disturbances}

The term "crushed chest injury" implies considerable violence to the thorax, and this must result in damage to the

\footnotetext{
* Consultant, University Department of Anaesthetics, Glasgow Royal Infirmary.

† Consultant, University Department of Anaesthetics, Glasgow Royal Infirmary.
}

lungs, as suggested by Harley (1961) (Fig. 1). The disruption of alveolar structure, interstitial and intra-alveolar haemorrhage, and atelectasis due to plugging of the bronchioles with secretions and debris are evident. Alteration in the alveolar ventilation/blood perfusion ratio $(V / P$ ratio) is inevitable in the affected segments of the lungs. This leads to a reduction

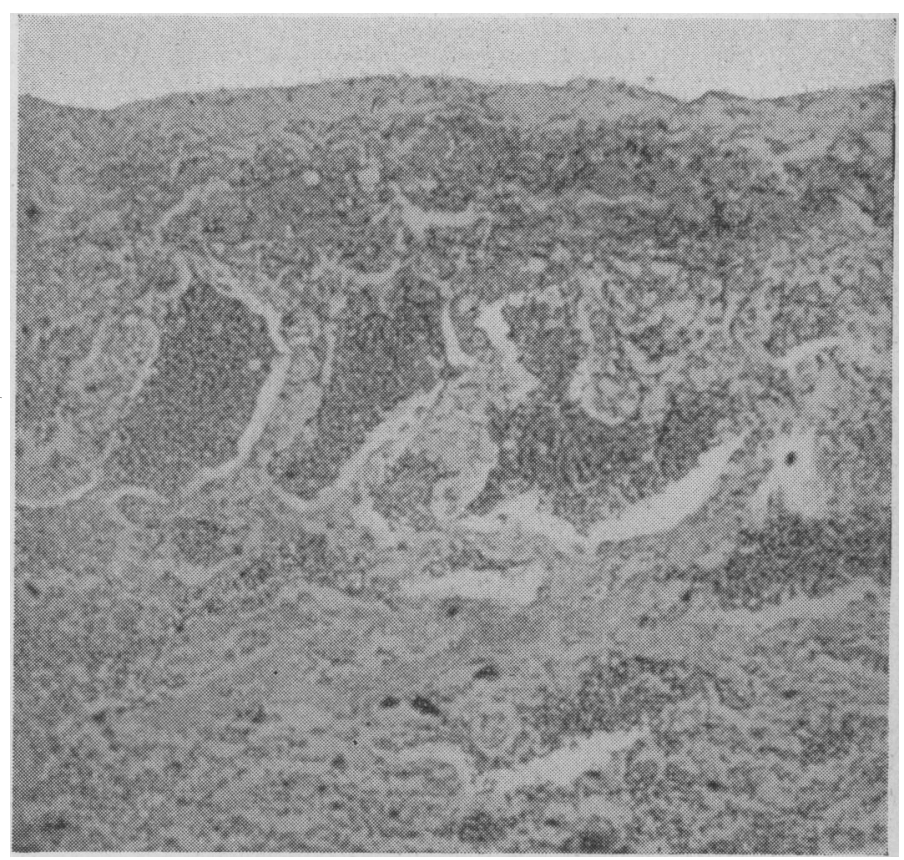

Fig. 1.-Demonstrating damage to the lungs. 